\section{Hypoglycemic shock and acute liver injury in a dog associated with xylitol toxicity}

\section{ABSTRACT}

An adult dog were evaluated for treatment loss of consciousness, convulsions, and severe tremors after ingestion of xylitol, a sugar alcohol used as a sweetener in various products. Clinical findings were noted as loss of consciousness, convulsions, and severe tremors, while physio-pathological findings included moderately to severely elevated serum activities of liver enzymes, hypoglycaemia and hypophosphatemia. To correct hypoglycaemia, dextrose was administered intravenously and to provide electrolyte homeostasis Izolen P was administered intravenously. Also, silymarin (Milk Thistle \& Beta Glucan Complex, Natur, Turkey) S-adenosylmethionine (Hepatiale Forte Advanced $\AA$, Vetexpert, Poland), Vit. E (Evicap ${ }^{\circledR}$, Koçak Farma, Turkey) and acetylcysteine (Mucomyst ${ }^{\circledR}$, UPSA, France) were used to correct acute liver damage. Values measured after the applied treatments showed that blood glucose levels and liver enzymes returned to normal, and the patient was discharged. Xylitol causes hypoglycaemia and acute liver damage in dogs after ingestion. As a growing number of products contain xylitol, clinicians should be aware that ingestion of xylitol could have life-threatening effects. This case report also carries the distinction of being the first xylitol toxicity reported in dogs in Turkey.

Keywords: Acute liver damage, dog, hypoglycaemia, liver enzymes, xylitol.

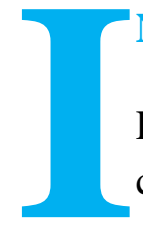

\section{NTRODUCTION}

Polyols (sugar alcohols) are nutritious sweeteners obtained by catalytic hydrogenation of the oxo group of natural sugars, i.e. by substituting an aldehyde or keto group with hydroxyl (Ladret et al., 2008). Discovered by Emil Fisher in 1891, xylitol is a 5-carbon sugar alcohol and used as an artificial sweetener (Ur-Rehman et al., 2015). Used as a sugar substitute for the first time in Scandinavian countries during World War II, xylitol was obtained from hardwood species such as Betula pendula (Dunayer \& Gwaltney-Brant, 2006). Xylitol has been used as a sugar substitute in diabetic patients in recent years because it tastes similar to sucrose but has fewer calories (Dills, 1989; Janket et al., 2019).

According to a study conducted between 2001 and 2011, xylitol has been reported to be found in various industrial products such as nutritional supplements such as chewing gum, mint candy, lollipop, some prescription medicines, various vitamins (multivitamin tablets, iron, vitamin D chewable tablets, etc.), coenzyme Q10, 5-hydroxytryptophan, chocolate, pudding, fruit preserves, jellies, jelly beans, beverage powders, toothpaste, mouth lozenges, moisturizing mouth sprays and mouthwash solutions (Dunayer, 2006).

\section{How to cite this article}

Hatipoğlu, D., Kahraman, O. (2021). Hypoglycemic shock and acute liver injury in a dog associated with xylitol toxicity. Journal of Advances in VetBio Science and Techniques, 6(2), 165170. https://doi.org/10.31797/vetbio.928753
Case Report

Durmuş HATİPOĞLU ${ }^{1 a}$ Okan KAHRAMAN ${ }^{2 b}$

${ }^{1}$ Department of Physiology,

Faculty of Veterinary

Medicine, Selcuk

University, Konya, Turkey

${ }^{2}$ Green Pet Veterinary

Polyclinic, Istanbul, Turkey

ORCID-

${ }^{\mathrm{a}} 0000-0003-3790-7821$

b0000-0003-0466-1474

Correspondence

Durmuş HATİPOĞLU

drhatip@selcuk.edu.tr

Article info

Submission: 27-04-2021

Accepted: 16-07-2021

Online First: 26-08-2021

e-ISSN: 2548-1150

doi prefix: $10.31797 /$ vetbio

- http://dergipark.org.tr/vetb

$\underline{\text { io }}$

This work is licensed under a Creative Commons Attribution 4.0 International License (c) (i) 
It has been suggested that the xylitol toxicity seen in dogs is related to severe hypoglycaemia caused by insulin secretion (Kuzuya et al., 1969). It is reported that xylitol increases insulin secretion 2.5-7 times more than the same amount of glucose in dogs (Kuzuya et al., 1966). Typical clinical symptoms such as ataxia, seizures and vomiting are observed in xylitol intoxication in dogs. Changes in the nervous system are associated with hypoglycaemia and usually occur approximately 30-60 minutes after xylitol intake. Approximately $0.15 \mathrm{~g} / \mathrm{kg}$ xylitol has been reported to cause hypoglycaemia (Dunayer \& Gwaltney-Brant, 2006). Researchers also state that an increase in liver enzymes occurs 8-12 hours after ingestion of xylene in dogs and severe liver failure is formed (Murphy \& Dunayer, 2018).

\section{CASE PRESENTATION}

A 10-year-old, $36 \mathrm{~kg}$, spayed female Golden Retriever was brought to the veterinary emergency clinic due to loss of consciousness, convulsions, and severe tremors. After the anamnesis, it was learned that the dog ate one package (180 g) of jelly tots containing xylitol approximately 1-1.5 hours ago. Xylitol was calculated to be approximately $8.2 \mathrm{~g} / \mathrm{kg}$ of body weight. The dog rectal body temperature was $39.3^{\circ} \mathrm{C}$, heart rate was 136 beats/min and respiratory rate was 21 breaths/min. The mucous membranes were pink and the capillary refill time was within the reference range. The abdominal area was saggy and there were no abdominal pain symptoms.

\section{DISCUSSION}

The initial diagnosis made included a complete blood count and serum chemical parameters. The blood glucose level found as $41 \mathrm{mg} / \mathrm{dl}$ showed that the dog had severe hypoglycaemia and the phosphorus level measured as $0.98 \mathrm{mg} / \mathrm{dl}$ showed that the dog had hypophosphatemia. All laboratory findings are shown in Table 1. While normal complete blood count values were noted in the laboratory findings, a slight increase was observed in haemoglobin $(\mathrm{Hg})$ amount and platelet counts; but serum alanine transferase (ALT, 273U/L) and serum aspartate transferase (AST, $242 \mathrm{U} / \mathrm{L}$ ) were found to be significantly increased (Table 1).

Table 1. Pre-treatment total blood count and serum biochemistry values.

\begin{tabular}{|c|c|c|c|c|c|}
\hline \multicolumn{3}{|c|}{ Total blood count values } & \multicolumn{3}{|c|}{ Serum biochemistry values } \\
\hline Parameters & Value & Reference ranges & Parameters & Value & Reference ranges \\
\hline WBC $\left(10^{\wedge} 9 / 1\right)$ & 12.19 & $6.00-17.00$ & $\operatorname{ALT}(\mathrm{U} / \mathrm{L})^{*}$ & 273 & $5-60$ \\
\hline LYM (10^9/I) & 4.08 & $1.00-4.80$ & $\operatorname{AST}(\mathrm{U} / \mathrm{L})^{*}$ & 242 & $5-55$ \\
\hline MONO $\left(10^{\wedge} 9 / 1\right)$ & 1.10 & $0.20-1.50$ & GGT (U/L) & 5 & $<=10$ \\
\hline GRA $\left(10^{\wedge} 9 / 1\right)$ & 7.01 & $3.00-12.00$ & ALP (U/L) & 61 & $10-150$ \\
\hline LY (\%) & 33.4 & $12.0-30.0$ & CREA $(\mathrm{mg} / \mathrm{dl})$ & 0.70 & $0.40-1.80$ \\
\hline MON (\%) & 9.0 & $2.0-6.0$ & $\mathrm{GLU}(\mathrm{mg} / \mathrm{dl})^{*}$ & 41 & $60-125$ \\
\hline GR $(\%)$ & 57.5 & $62.0-87.0$ & UREA $(\mathrm{mg} / \mathrm{dl})$ & 31.5 & $20.0-50.0$ \\
\hline $\operatorname{RBC}\left(10^{\wedge} 12 / 1\right)$ & 8.20 & $5.50-8.50$ & TBIL (mg/dl) & 0.00 & $<=0.40$ \\
\hline HGB (g/dl) & 18.4 & $12.0-18.0$ & $\mathrm{Ca}(\mathrm{mg} / \mathrm{dl})$ & 8.4 & $7.5-11.3$ \\
\hline HCT (\%) & 53.08 & $37.00-55.00$ & $\mathrm{P}(\mathrm{mg} / \mathrm{dl})^{*}$ & 0.98 & $2.20-5.50$ \\
\hline MCV (fl) & 65 & 60-77 & TP (g/dl) & 6.6 & 5.4-7.7 \\
\hline MCH (pg/dl) & 22.4 & $19.5-24.5$ & ALB (g/dl) & 2.7 & $2.3-3.8$ \\
\hline MCHC (g/dl) & 34.7 & $31.0-34.0$ & TC (mg/dl) & 209 & $<=270$ \\
\hline RDWc (\%) & 18.7 & & CK (U/L)* & 481 & $20-200$ \\
\hline PLT (10^9/l) & 542 & $200-500$ & AMY (U/L) & 727 & $500-1500$ \\
\hline PCT (\%) & 0.51 & & GLB（g/dl) & 3.90 & \\
\hline MPV (fl) & 9.5 & $3.9-11.1$ & ALB/GLB & 0.69 & \\
\hline PDWc (\%) & 39.1 & & $(\mathrm{~g} / \mathrm{dl})$ & & \\
\hline
\end{tabular}

* Parameters that are outside the reference range. 
To correct hypoglycaemia, 5\% dextrose (1 $\mathrm{ml} / \mathrm{kg}$ ) and to provide electrolyte homeostasis, Izolen $\mathrm{P}$ was administered intravenously in a total of $300 \mathrm{ml}$. In addition, silymarin (Milk Thistle \& Beta Glucan Complex Natur, Turkey) (20-50 mg/kg/day PO), S-adenosylmethionine (Hepatiale Forte Advanced ${ }^{\circledR}$, Vetexpert, Poland) $\left(17-20\right.$ mg/kg/day PO), Vit. E (Evicap ${ }^{\circledR}$, Koçak Farma, Turkey) (400 IU x 1) and acetylcysteine (Mucomyst $^{\circledR}$, UPSA, France) were used to correct acute liver damage. Values measured after the applied treatments showed that blood glucose levels and liver enzymes returned to normal, and the patient was discharged (Table 2).

Table 2. Post-treatment total blood count and serum biochemistry values.

Serum biochemistry values

\begin{tabular}{|lcc|}
\hline Parameters & Value & Reference ranges \\
\hline ALT (U/L) & 55 & $5-60$ \\
\hline AST (U/L) & 47 & $5-55$ \\
\hline ALP (U/L) & 61 & $10-150$ \\
\hline GLU (mg/dl) & 64 & $60-125$ \\
\hline P (mg/dl)* & 0.98 & $2.20-5.50$ \\
\hline ALB (g/d) & 2.7 & $2.3-3.8$ \\
\hline
\end{tabular}

* Parameters that are outside the reference range.

Due to the increasing market share of products containing xylitol in the food industry over the past few years, the number of xylitol toxicosis reported in dogs has also increased (Dunayer, 2006; Dunayer \& Gwaltney-Brant, 2006; Xia et al., 2009). Although increased insulin releases have been documented in rabbits, goats and cows, it was noted that xylitol does not cause similar insulin release or blood glucose changes in horses, rats, and humans (Kuzuya et al., 1971). It was reported that oral administration of 100,500 , and $1000 \mathrm{mg} / \mathrm{kg}$ of xylitol in cats is within reference ranges of both liver enzymes and blood glucose values (Jerzsele et al., 2018). However, xylitol intake in dogs causes a dose-dependent insulin release that is higher than the response to equal doses of glucose (Hirata et al., 1966; Kuzuya et al., 1966). Peak serum insulin concentrations were observed to be 6-times higher than glucose following xylitol intake and thus severe hypoglycaemia was observed in dogs (DuHadway et al., 2015; Kuzuya et al., 1969). It was experimentally reported that dogs that were given 1 or $4 \mathrm{~g}$ of oral xylitol per kilogram of body weight showed rapid increases in plasma insulin concentrations within 20 minutes and reached the peak at 40 minutes (Xia et al., 2009).
Approximately $80 \%$ of xylitol metabolism occurs in the liver (Dunayer, 2004) and where it is rapidly oxidized to D-xylulose, then metabolized to glucose, glycogen, and lactate via the pentose-phosphate pathway (Froesch \& Jakob, 1974). The remainder of xylitol (20-30\%) is metabolized by the fat stores, erythrocytes, myocardium, kidneys and lungs, where they are then converted into water and carbon dioxide through carbohydrate metabolism (Ur-Rehman et al., 2015). Xylitol itself can directly stimulate pancreatic $\beta$-cells to secrete insulin; the increased insulin level then causes significant decreases in blood glucose levels. Hypoglycaemia affects the red blood cell membranes, causing bilirubin to break down and release (Peterson, 2013).

Although no $\mathrm{LD}_{50}$ was determined for xylitol intake in dogs, toxicosis has been reported with $0.1 \mathrm{~g} / \mathrm{kg}$ hypoglycaemia and $0.5 \mathrm{~g} / \mathrm{kg}$ hepatic necrosis (Piscitelli et al., 2010). Vomiting in dogs due to the development of hypoglycaemia 30-60 minutes after a meal is usually seen as the first sign of xylitol toxicosis, followed by weakness, ataxia and lethargy (Dunayer, 2006). In this case, the dog that swallowed xylitol at a dose of $8.2 \mathrm{~g} / \mathrm{kg}$ was exposed to a dose 
approximately 16.4 times the dose in which hepatic necrosis was seen. Although the first clinical symptoms such as tremor, loss of consciousness, convulsions, and severe hypoglycaemia observed after xylitol intake coincided with the previously reported xylitol toxicosis scenario, no sign of vomiting were observed. Xylitol induces hyperinsulinemia in dogs by stimulating the synthesis and secretion of insulin (DuHadway et al., 2015). The exact mechanism of the xylitol-induced increase in insulin secretion is unclear; however, a study conducted in anaesthetized dogs showed that xylitol directly stimulated insulin secretion by pancreatic islet $\beta$ cells rather than its metabolites (DuHadway et al., 2015). As expected, increased insulin concentrations after xylitol intake caused a decrease in blood glucose (Table 1). Clinical manifestations such as weakness, depressive activities, tremors, loss of consciousness, and convulsions resulting from a dramatic decrease in blood glucose concentrations were a possible consequence of hypoglycaemia. Intravenous Dextrose and Izolen P, used to prevent and treat hypoglycaemia, yielded successful results (Table 2). The severe increase in liver enzymes such as ALT and AST were similar to previously reported cases and liver enzyme values of dogs for whom experimental xylitol toxicosis was formed (Table 1) (Dunayer \& Gwaltney-Brant, 2006; Schmid \& Hovda, 2016; Xia et al., 2009). Xylitol is mainly metabolized in the liver (Förster, 1975) and this metabolic process needs ATP (Vincent et al., 1989). When large amounts of xylitol are taken into the bloodstream, ATP in hepatocytes is depleted, resulting in hepatocyte necrosis and thus elevation of plasma ALT and AST (Dunayer\& Gwaltney-Brant, 2006). The dramatic increase in ALT and AST is consistent with hepatocellular damage caused by the release of soluble cytosolic enzymes from the liver due to altered cell membrane permeability. As plasma GGT concentration did not change, liver damage was not considered to be associated with effects on the biliary system. Sadenosylmethionine was used to repair acute liver damage that occurred and to support liver function comprehensively and to help regenerate hepatocytes, and vitamin E, a good antioxidant, was used to eliminate the oxidative damage to the liver, and values were found to return to normal (Table 2).

The cause of hepatic necrosis in xylitol toxicosis in dogs is not fully known. Xylitol results in high concentrations of cellular nicotinamide adenine dinucleotide $\left(\mathrm{NAD}^{+}\right)$that produces reactive oxygen species in the liver that can damage cellular membranes and macromolecules and reduce the viability of hepatocytes (Dunayer \& Gwaltney-Brant, 2006). $\mathrm{NAD}^{+}$is an important cofactor that functions as an electron carrier in the organism and is reduced to NADH by glycolysis in the cytoplasm. (Verdin, 2015). Cytosolic NADH directs the osmotic-chemical synthesis of ATP as an energy storage molecule after it is transported to the mitochondria (Kim et al., 2019). Mitochondria have their own enzymatic mechanism to alleviate and eliminate ROS against cell homeostasis and oxidative stress damage (Moreno-Sánchez et al., 2018). When the mitochondrial ROS level exceeds the antioxidant defence system, the permeability of the mitochondrial inner membrane is lost, and as a result, it can lead to apoptotic cell death (Han et al., 2018; Ralph et al., 2015; Rottenberg \& Hoek, 2017). To relieve oxidative stress, glutathione peroxidase (GPx), glutathione reductase (GR), thioredoxin reductase (TrxR), and superoxide dismutase (SOD) are transported from cytosol to mitochondria (Marí et al., 2009; Ribas et al., 2014). Studies have reported that high NADPH levels provide protection against ROS, but low NADPH levels cause cellular damage by causing ROS accumulation (Marí et al., 2009). GSH is required in cell detoxification and many metabolic processes, and acute liver damage caused by oxidative stress in dogs with low glutathione transferase activity or low natural protective mechanisms (Watanabe et al., 2004) may develop due to xylitol toxicity resulting in 
$\mathrm{NAP}^{+}$, the final product in metabolism. Both $\mathrm{NADPH} / \mathrm{NADP}^{+}$and GSH / GSSG ratios are very important for improving oxidative stress (Moreno-Sánchez et al., 2018).

While the use of xylitol in the food industry has increased in recent years, for patients, it is especially critical to be vigilant about the use of xylitol, careful evaluation of product labels, and correct management of the treatment process, especially by veterinarians and dog owners. As a result, there is no antidote to xylitol toxicosis, and emergency treatment methods include stabilizing blood glucose, protecting the liver, and providing more care when needed. Closely monitoring blood glucose levels and providing dextrose supplements as needed is critical in the early stages for treatment modalities of xylitol toxicosis in dogs (Schmid \& Hovda, 2016). This report revealed that xylitol toxicosis in dogs affects vital functions, and acute liver insufficiency and severe hypoglycaemia occurring as a result of xylitol toxicosis can be successfully treated with aggressive therapy.

\section{ACKNOWLEDGMENT}

Ethical approval: Permission was obtained from the patient owner on 05.02.2021 with a "treatment and information consent form".

Conflict of interest: The authors declared that there is no conflict of interest

\section{KAYNAKLAR}

Dills, W. L. (1989). Sugar Alcohols as Bulk Sweeteners. Annual Review of Nutrition, 9(1), 161-186. https://doi.org/10.1146/annurev.nu.09.070189.001113

DuHadway, M. R., Sharp, C. R., Meyers, K. E., \& Koenigshof, A. M. (2015). Retrospective evaluation of xylitol ingestion in dogs: 192 cases (2007-2012). Journal of Veterinary Emergency and Critical Care, 25(5), 646-654.

Dunayer, E. K. (2004). Hypoglycemia following canine ingestion of xylitol-containing gum. Vet Hum Toxicol, 46(2), 87-88.

Dunayer, E. K. (2006). New findings on the effects of xylitol ingestion in dogs. Veterinary Medicine-Bonner Springs Then Edwardsville, 101(12), 791.
Dunayer, E. K., \& Gwaltney-Brant, S. M. (2006). Acute hepatic failure and coagulopathy associated with xylitol ingestion in eight dogs. Journal of the American Veterinary Medical Association, 229(7), 1113-1117. https://doi.org/10.2460/javma.229.7.1113

Förster, H. (1975). The metabolism of monosaccharides and polyoles. Infusionstherapie und klinische Ernahrung, 2(3), 187-201.

Froesch, E., \& Jakob, A. (1974). The metabolism of xylitol. Sugars in nutrition, 241-258.

Han, S. J., Choi, H. S., Kim, J. I., Park, J.-W., \& Park, K. M. (2018). IDH2 deficiency increases the liver susceptibility to ischemia-reperfusion injury via increased mitochondrial oxidative injury. Redox biology, 14, 142-153.

Hirata, Y., Fujisawa, M., Sato, H., Asano, T., \& Katsuki, S. (1966). Blood glucose and plasma insulin responses to xylitol administrated intravenously in dogs. Biochemical and Biophysical Research Communications, 24(3), 471-475. https://doi.org /https://doi.org/10.1016/0006-291X(66)90185-9

Janket, S. J., Benwait, J., Isaac, P., Ackerson, L. K., \& Meurman, J. H. (2019). Oral and Systemic Effects of Xylitol Consumption. Caries Research, 53(5), 491501. https://doi.org/10.1159/000499194

Jerzsele, Á., Karancsi, Z., Pászti-Gere, E., Sterczer, Á., Bersényi, A., Fodor, K., Szabó, D., \& Vajdovich, P. (2018). Effects of p.o. administered xylitol in cats. Journal of Veterinary Pharmacology and Therapeutics, 41(3), 409-414. https://doi. org/https://doi.org/10.1111/jvp.12479

Kim, J., Lee, S. H., Tieves, F., Paul, C. E., Hollmann, F., \& Park, C. B. (2019). Nicotinamide adenine dinucleotide as a photocatalyst. Science advances, 5(7), eaax0501.

Kuzuya, T., Kanazawa, Y., Hayashi, M., Kikuchi, M., \& Ide, T. (1971). Species Difference in Plasma Insulin Responses to Intravenous Xylitol in Man and Several Mammals. Endocrinologia Japonica, 18(4), 309-320. https://doi.org/10.1507/endocrj1954.18.309

Kuzuya, T., Kanazawa, Y., \& Kosaka, K. (1966). Plasma insulin response to intravenously administered xylitol in dogs. Metabolism - Clinical and Experimental, 15(12), 1149-1152. https://doi.org/ 10.1016/0026-0495(66)90105-3

Kuzuya, T., Kanazawa, Y., \& Kosaka, K. (1969). Stimulation of Insulin Secretion by Xylitol in Dogs1. Endocrinology, 84(2), 200-207. https://doi.org/10. 1210/endo-84-2-200

Ladret, M., Le Bot, Y., Nesvadba, S., Ostermann, E., \& Ribadeau-Dumas, G. (2008). Polyols: their properties and applications in sugar-free chewing gum. Formulation and Production of Chewing and Bubble Gum, 133-156.

Marí, M., Morales, A., Colell, A., García-Ruiz, C., \& Fernández-Checa, J. C. (2009). Mitochondrial glutathione, a key survival antioxidant. Antioxidants \& redox signaling, 11(11), 2685-2700. 
Moreno-Sánchez, R., Marín-Hernández, Á., GallardoPérez, J. C., Vázquez, C., Rodríguez-Enríquez, S., \& Saavedra, E. (2018). Control of the NADPH supply and GSH recycling for oxidative stress management in hepatoma and liver mitochondria. Biochimica et Biophysica Acta (BBA)-Bioenergetics, 1859(10), 1138-1150.

Murphy, L. A., \& Dunayer, E. K. (2018). Xylitol Toxicosis in Dogs: An Update. Veterinary Clinics of North America: Small Animal Practice, 48(6), 985990. https://doi.org/10.1016/j.cvsm.2018.06.004

Peterson, M. E. (2013). Xylitol. Topics in Companion Animal Medicine, 28(1), 18-20. https://doi. org/https://doi.org/10.1053/j.tcam.2013.03.008

Piscitelli, C. M., Dunayer, E. K., \& Aumann, M. (2010). Xylitol toxicity in dogs. Compend Contin Educ Pract Vet, 32(2), E1-E4.

Ralph, S. J., Pritchard, R., Rodríguez-Enríquez, S., Moreno-Sánchez, R., \& Ralph, R. K. (2015). Hitting the bull's-eye in metastatic cancers-NSAIDs elevate ROS in mitochondria, inducing malignant cell death. Pharmaceuticals, 8(1), 62-106.

Ribas, V., García-Ruiz, C., \& Fernández-Checa, J. C. (2014). Glutathione and mitochondria. Frontiers in pharmacology, 5, 151.

Rottenberg, H., \& Hoek, J. B. (2017). The path from mitochondrial ROS to aging runs through the mitochondrial permeability transition pore. Aging cell, 16(5), 943-955.

Schmid, R. D., \& Hovda, L. R. (2016). Acute Hepatic Failure in a Dog after Xylitol Ingestion. Journal of Medical Toxicology, 12(2), 201-205. https://doi.org/10.1007/s13181-015-0531-7

Ur-Rehman, S., Mushtaq, Z., Zahoor, T., Jamil, A., \& Murtaza, M. A. (2015). Xylitol: A Review on Bioproduction, Application, Health Benefits, and Related Safety Issues. Critical reviews in food science and nutrition, 55(11), 1514-1528. https://doi.org /10.1080/10408398.2012.702288

Verdin, E. (2015). $\mathrm{NAD}^{+}$in aging, metabolism, and neurodegeneration. Science, 350(6265), 1208-1213. https://doi.org/10.1126/science.aac4854

Vincent, M. F., Van Den Berghe, G., \& Hers, H. G. (1989). D-Xylulose-induced depletion of ATP and Pi in isolated rat hepatocytes. The FASEB journal, 3(7), 1855-1861.

Watanabe, T., Sugiura, T., Manabe, S., Takasaki, W., \& Ohashi, Y. (2004). Low glutathione S-transferase dogs. Archives of Toxicology, 78(4), 218-225. https://doi.org/10.1007/s00204-003-0536-x

Xia, Z., He, Y., \& Yu, J. (2009). Experimental acute toxicity of xylitol in dogs. Journal of Veterinary Pharmacology and Therapeutics, 32(5), 465-469. 